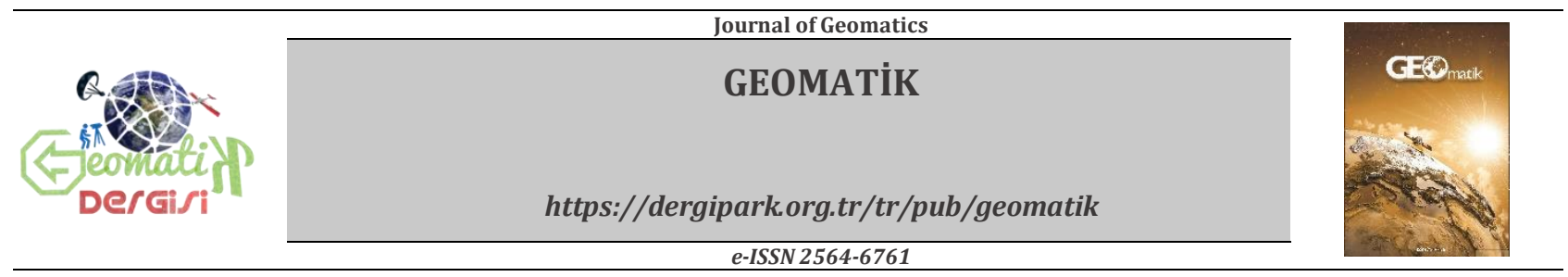

\title{
Mersin ilindeki kentsel büyümenin yer yüzey sıcaklığı üzerine etkisinin araştırılması
}

\author{
Osman Orhan*1 \\ 1Mersin Üniversitesi, Mühendislik Fakültesi, Harita Mühendisliği Bölümü, Mersin, Türkiye
}

\author{
Anahtar Kelimeler \\ Mersin \\ Kentsel Isll Ada \\ YYS \\ Landsat \\ Kentlessme
}

\begin{abstract}
ÖZ
Kentlerde, zaman içerisinde hızlı nüfus artışı ile birlikte görülen kentleşme ve sanayileşme doğal alanların, yok edilerek beton, asfalt vb. güneș enerjisini absorbe eden yüzeylere dönüşmesine neden olmuştur. Kentleşme, kent merkezlerindeki sıcaklığın çevresindeki tarım arazileri, orman vb. doğal alanlarından daha fazla olmasına neden olmaktadır. Bu durum lokal iklim değișikliği, hava kirliliği, enerji tüketimi, sağllk sorunları vb. olayların kaynağı olan kentsel ısı adası etkisini ortaya çıarmaktadır. $\mathrm{Bu}$ çalışmanın amacı, son zamanlarda hızlı bir nüfus artışının yaşandığı Mersin ilindeki kentleşmenin Yer Yüzey Sıcaklığı üzerindeki etkisinin araştırılmasıdır. Bu kapsamda, Landsat-5 TM ve Landsat-8 OLI uydu görüntüleri kullanılarak 1990-1999-2007-20112018 yıllarına ait sıcaklık haritaları üretilmiștir. Aynı zamanda 1990 ve 2018 yıllarında kentsel alanlarının belirlenmesi için CORINE arazi kullanımı/örtüsü verisinden faydalanılmıştır. Çalışma sonucunda 28 yıllık periyotta birçok doğal alanların yok edilerek yapay alanlara dönüştüğü ve bunun neticesinde Mersin kent merkezi için ortalama $6^{\circ} \mathrm{C}$ civarında sıcaklık artışı yaşandığı gözlenmiștir.
\end{abstract}

\section{Investigation of the effect of urban expansion on surface temperature in Mersin city}

\author{
Keywords \\ Mersin \\ Urban Heat Island \\ LST \\ Landsat \\ Urbanization
}

\begin{abstract}
Urbanization and industrialization, which is seen with rapid population growth in cities over time, causes the destruction of natural areas and transforms them into surfaces (concrete, asphalt, etc.) that absorb solar energy. Urbanization causes the temperature in urban centers to be higher than the natural areas such as agricultural lands and forests. This is known as the urban heat island and causes local climate change, air pollution, energy consumption, health problems. The aim of this study is to investigate the effect of urbanization on the surface temperature of the city of Mersin, where there has been a rapid population increase recently. In this context, the Land Surface Temperature maps of the years 1990-1999-2007-2011-2018 were produced using Landsat-5 TM and Landsat-8 OLI satellite images. Also, CORINE land use/cover data were used to identify urban areas in 1990 and 2018. As a result of this study, it was observed that many natural areas were destroyed and transformed into artificial areas in 28 years period and as a result of this, an average temperature increase of around $6{ }^{\circ} \mathrm{C}$ was observed for Mersin city center.
\end{abstract}




\section{GíRiş}

Hükümetler arası İklim Değișikliği Paneli(IPCC), küresel iklim değişikliğinin temel nedeninin insan faaliyetleri sonucunda ortaya çlkan sera gazı emisyonlarının olduğunu ve bu emisyon değerlerinde ciddi bir artışın gözlendiğini ortaya koymuştur (IPCC, 2013). Sera gazları, yaklaşık olarak \%72 oranında Karbondioksit (CO2), \%19 oranında Metan (CH4) ve diğer gazlardan oluşmaktadır. Karbondioksit oranındaki ciddi artış ilk olarak fosil ve biokütle yakıtların kullanılmasından kaynaklanıyor. İkincil olarak da arazi örtüsü ve arazi kullanımındaki değişim olarak gösterilmektedir. Ayrıca, katı atık depolama sahaları metan gazı, çimento üretim alanları karbondioksit, gübre kullanımı ve naylon üretimi di-azot monoksit gazını ve klimalar sera gazı emisyonlarını artırmaktadır. Tarım aktivitelerinin yapılması için doğal alanlardan arazi açılması ve bunun yanı sıra ormanların yok edilmesi koyu renkli yüzeylerin artmasına neden olmakta ve bu yüzeylerin artması ile birlikte gelen güneş radyasyonu yansımaktan çok emilmektedir. Ayrıca, ormanların tahrip edilmesiyle, karbondioksiti tutan ve depolayan ağaç ve bitkiler azalmaktadır. Şehirleşme, şehir ısı adalarının, yani şehirlerde çevrelerine göre daha sıcak alanların oluşmasına yol açmaktadır (Ekinci, 2016; Tonyaloğlu, 2019). İklim değişikliğinin neden olduğu yağış rejiminden oluşan değişiklikler ile seller, deniz seviyesindeki yükselmeler ve su sıkıntıları yaşanmaktadır. Bu değişiklikler nedeniyle delta alanları zarar görmekte, sıcaklık değerlerindeki yükselmelerden dolayı çölleşme ve kurallıklarda artışlar gözlenmekte, tarım sahalarının artışı ve yaz aylarındaki yağıș miktarındaki azalış nedeni ile de yüzey ve yer altı su kaynaklarına duyulan ihtiyacın artması ve buna bağlı olarak doğal kaynakların tükenmesi gibi olumsuz etkiler görülmektedir.

Sınırlandırılamayan kentsel yayılma ve insan kaynaklı iklim değișikliği, 21. yüzyılın geri dönüșü olmayan, kaçınılmaz iki büyük sorunu olarak gösterilmektedir. Birleşmiş Milletler Ekonomik ve Sosyal İşler Dairesi(The United Nations Department of Economic and Social Affairs-UN DESA)'nin tahminlerine göre, 2050'de dünya nüfusunun 10 milyar olacağı ve dünya nüfusunun yüzde 68 'inin kentlerde yaşamasının öngörüldüğ̈ü belirtilmiştir. 1990 yılında 10 milyonun üzerinde nüfusa sahip sadece 10 mega kentin olduğuna ișaret edilen raporda, 2030'a kadar mega kent sayısının 43'e ulaşacağı belirtilmiştir. Kontrolsüz kentsel yayılma, iklim değişikliğinde önemli paya sahip olan bir faktördür. Kentlerde yaşayan nüfus artışındaki hızlanma ile birlikte kentlerin merkezinde ve çevresinde bulunan doğal yeşil alanlar, yerini beton, asfalt vb. Isı adası etkisi ortaya çıkartacak yüzeylere bırakmaktadır (Moradi ve Görer Tamer,2017; Kuşak ve Küçükali, 2019). Isı adası olarak tanımlanan (Urban Heat Island-UHI) kentleşme ve sanayileşme etkisi, atmosferdeki ısı ve su döngüsünü etkileyerek küresel bir sorun haline gelen iklim değişikliğinde önemli bir rol oynamaktadır. (Demircan vd. 2017; Yüksel ve Yılmaz, 2008).

Uzaktan Algılama, yer yüzeyleri hakkında güncel, doğru ve detaylı bilgi sağlayan önemli bir veri kaynağıdır. Uzaktan algılama görüntüleri birçok çalışmada etkin bir biçimde kullanılmaktadır. Bunlar; yeryüzü planlaması, okyanus akıntılarının izlenmesi, maden araştırmaları, ormanların güncel durumlarının incelenmesi, tarımsal alanlardaki analizler ve deformasyon çalışmalarıdır. (Pardolguzquiza vd.,2010; Orhan vd., 2014; Şekertekin, vd. 2016; Calò vd. 2018). Bu teknoloji ayrıca çok zamanlı uydu görüntüleri ve elektromanyetik spektrumun kızılötesi ve termal bölgelerini kullanarak kentlerdeki arazi kullanımı/arazi örtüsünde meydana gelen değişimlere bağlı olarak oluşan kentsel isl adaların belirlenmesi ve araştırılması çalışmalarında kullanılmaktadır (Özkök vd. 2017;Tonyaloğlu, 2019; Şekertekin ve Marangoz, 2019). Termal veriler ilgili bölgelerin çok zamanlı Yer Yüzey Sıcaklığı (YYS) haritalarının oluşturulmasında başarıyla kullanılmaktadır. YYS'nı gözlemlemek, artan atmosferik sera gazları ile arazi yüzey sıcaklığı arasındaki ilişkiyi anlamak ve kentlerdeki artan yer yüzey sıcaklığındaki artışın etkisini analiz etmek açısından önemlidir (Balçık, 2014; Orhan \& Yakar, 2016; Orhan vd. 2019; Şekertekin \& Arslan, 2019).

$\mathrm{Bu}$ çalışma kapsamında, Mersin ilindeki hızla artan kentleşme ve buna bağlı olarak meydana gelen sıcaklık haritalarındaki değişim uzaktan algılama verilerine dayalı olarak incelenmiștir. YYS haritalarının üretilmesinde görüntü kaynağı olarak Lansat-5 TM ve Landsat-8 OLI uydu görüntüleri kullanılmıştır. 1990-1999-2007-2012-2018 yıllarına ait Temmuz ve Ağustos ayı sıcaklık değişimleri incelenmiş ve elde edilen sıcaklık haritaları CORINE verileri ile karşılaştırılmıştır.

\section{2. ÇALIȘMA ALANI}

Mersin; Akdeniz bölgesi içerisinde yer alan ve Türkiye'nin önde gelen metropol kentlerine alternatif olarak gelişen bir kent olma özelliği taşımaktadır. Mersin, üç kıtanın birleştiği Anadolu Yarımadası'nın Orta Güney bölgesinde yer almaktadır. Doğusunda Adana, batısında Antalya kuzeyinde ise Karaman ve Konya illeri ile çevrilidir(Şekil-1). Mersin, yüzölçümü olarak 16010 $\mathrm{km}^{2}$ bir alanı kapsamaktadır. 36-37을 kuzey enlemleri ve 33-35 doğu boylamları arasında yer alan şehrin 321 km'lik deniz sınırı vardır. Mersin'in önemli bir Doğu Akdeniz liman kentine dönüşmesi ve çevrede yaşanan çeşitli gelişmeler sonucu farklı coğrafyalardan kente göçün artması ile birlikte son zamanlarda ciddi oranda doğal alanların yok edilerek kentsel yayılmalar görülmektedir (MersinÇDP, 2013). 


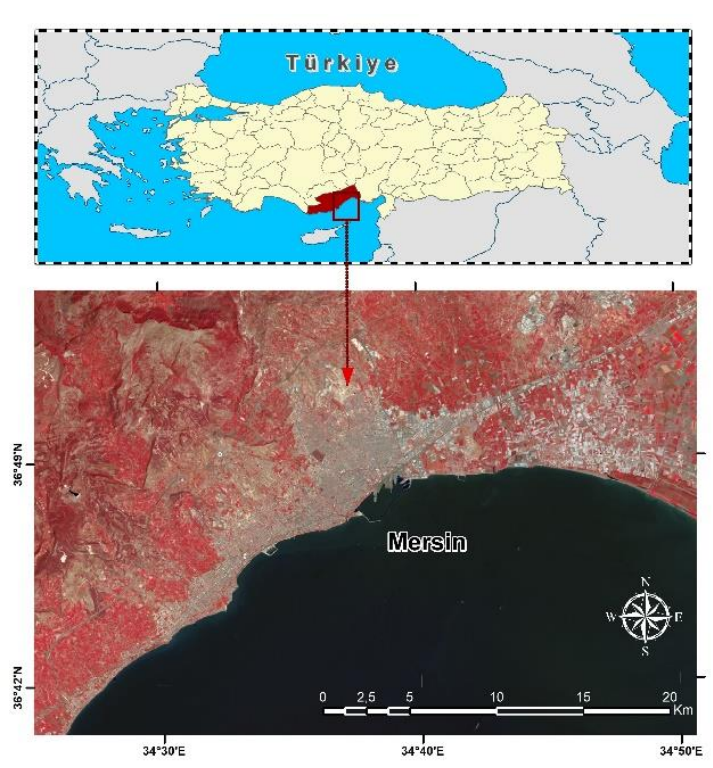

Şekil 1. Çalışma alanı

\section{MATERYAL ve METHOD}

Mersin şehir merkezi ve çevresine ait kentleşmenin ortaya çıkarmış olduğu sıcaklık değişiminin etkilerinin araştırılması için Landsat-5 TM/ 8 OLI uydu görüntüleri temel veri olarak kullanılmıştır. Kentleşme alanlarının tespit edilmesi içinde CORINE arazi örtüsü/kullanımı verisi kullanılmıştır.

Tablo 1. YYS haritalarının üretilmesi için kullanılan uydular ve görüntü çekim tarihleri

\begin{tabular}{ll}
\hline Uydu & Görüntü Tarihi \\
\hline Landsat-5 TM & $29 / 08 / 1990$ \\
\hline Landsat-5 TM & $21 / 07 / 1999$ \\
\hline Landsat-5 TM & $27 / 07 / 2007$ \\
\hline Landsat-5 TM & $23 / 08 / 2011$ \\
\hline Landsat-8 OLI & $10 / 08 / 2018$ \\
\hline
\end{tabular}

\subsection{Yer Yüzey Sıcaklık Haritalarının Üretilmesi}

Landsat-5 TM (termal bant) verisini kullanarak YYS'nı elde etmek için öncelikle sensor piksel değerlerini eşitlik-1 ile spektral radyans değerlerine dönüşümü sağlanır (Chander ve Groeneveld, 2009).

$$
L \lambda=\frac{L \max \lambda-L \min \lambda}{Q \operatorname{calmax}-Q \operatorname{calmin}} \times(Q c a l-Q \operatorname{calmin})+L \min \lambda
$$

Burada; $L \lambda$ sensördeki spektral radyans değeri, Qcal dijital piksel değeri, Qcal ${ }_{\text {max }}$ ve Qcal maksimum ve minimum dijital piksel değeri, $L_{\max }$ ve $L_{\min }$ ise Qcal $_{\max }$ ve Qcalmin 'e göre ölçeklendirilen spektral yansıtım değerini ifade etmektedir.

Aşağıdaki eşitlik ile Landsat-8 OLI (bant 10) için sensor piksel değerlerini spektral radyans değerlerine dönüşümü sağlanır.

$$
L \lambda=\mathrm{Ml} \times \mathrm{Qcal}+\mathrm{Al}
$$

Burada; ; $L \lambda$ sensördeki spektral radyans değerini, ML banda özgü ölçekleme çarpan faktörünü, Qcal dijital piksel değerini ifade eder (Barsi vd. 2014).

Eşitlik-3 ile uydunun termal bandından elde edilmiş olan spektral yansıtım değerleri kullanılarak sensör parlaklık sıcaklığı hesaplanmaktadır (Chander ve Markham, 2003; Coll vd, 2010; Orhan vd. 2014).

$$
T b=\frac{K 2}{\ln ((K 1 / L \lambda)+1)}
$$

Burada; Tb sensör parlaklık sıcaklık değerini,

$\mathrm{L} \lambda$ spektral radyans değerini, K1, K2 Landsat-5 ve Landsat-8 ait spesifik termal dönüşüm sabitlerini ifade eder (Avdan ve Jovanovska, 2016).

Sensör parlaklık sıcaklık değerine yer yüzey yayınırlı̆̆ı (emissivity) düzeltmesi yapılarak gerçek yüzey sıcaklığını temsil eden YYS elde edilir (eşitlik$4)$.

$$
T s=\frac{T b}{1+\left(\lambda \times \frac{T b}{\frac{h * c}{b}}\right) \ln \varepsilon \lambda}
$$

Burada; YYS hesabı için, $\lambda$ gelen termal bant dalga boyu (Landsat 4,5,7 için $11.45 \mu \mathrm{m}$ / Landsat-8 bant 10 için $10.895 \mu \mathrm{m}), \quad \mathrm{h}$ Planck sabiti(6.626*10-34Js), b Boltzmann sabiti $\left(1.38^{*} 10-23 \mathrm{~J} / \mathrm{K}\right)$, c ışık hızı $\left(2.998^{*} 108 \mathrm{~m} / \mathrm{s}\right)$ ve $\varepsilon \lambda$ piksele karşılık gelen yayınırlık değerini ifade eder. YYS haritalarını santigrat derece cinsinden sonuç elde etmek için, YYS değerine mutlak sıfır eklenerek revize edilmiştir.

Yayınırlık, cisme gelen toplam ışın enerjisinin, emilen ışın enerjisine oranı olarak ifade edilmektedir. Cisim ne kadar siyah ve mat ise yayınırlığı yüksek iken yansıtıcılığı artıkça yayınırlık değeri düşmektedir (Şekertekin ve Marangoz, 2019). YYS'nı tahmin etmek için yer yüzey yayınırlı̆̆ını-YYY $(\varepsilon)$ bilinmelidir. Yayınırlık değeri aşağıdaki eșitlik ile hesaplanır (Sobrino vd. 2004).

$$
\varepsilon \lambda=\varepsilon v \lambda P v+\varepsilon s \lambda(1-P v)+\mathrm{C} \lambda
$$

Burada;

$\varepsilon v$ ve $\varepsilon S$ bitki ve toprak yayllım değerlerini, $P v$ bitki örüntüsü oranını,

$\mathrm{C} \lambda$ - ortalama arazi pürüzlülüğünü ifade etmekte (düz araziler için C $=0$ ) (Sobrino, Caselles, ve Becker 1990).

Bu çalışmada, yer yüzey yayınırlığı belirlenmesi için NDVI eşik algoritması kullanılmıştır (Sobrino ve Raissouni 2000). Yer yüzey yayınırlı̆ı için NDVI kullanılarak üç farklı arazi tipi için (kayaç ve toprak / bitki örtüsü / kayaç ve bitki örtüsü karışımı) elde edilmiştir.

$P v$; Bitki örtüsü oranının hesaplanması için aşağıdaki eşitlikler kullanılmaktadır. 


$$
P v=\left[\frac{N D V I-N D V I \min }{N D V I \max -N D V I \min }\right]^{2}
$$

$$
N D V I=\frac{N I R-R E D}{N I R+R E D}
$$

Landsat-5 TM için YYY; NDVI değeri eğer 0,2'nin altında ise yüzeyin kayaç ve toprağın temsil ettiği ve bu durumda 0.97 yayınırlık değerinin kullanılması, NDVI değeri eğer 0,2 ile 0,5 arasında ise yüzeyin kayaç ve bitki örtüsü karışımını temsil ettiği ve bu durumda eşitlik 8'nin kullanılarak yayınırlık değerinin bulunması, NDVI değeri eğer 0,5'nin üstünde ise yüzeyin bitki örtüsü ile kaplı olduğu ve bu durumda 0.97 yayınırlık değerinin kullanılması önerilmiştir (Sobrino vd. 2004; Sobrino vd. 2008 ).

$$
\varepsilon T M 6=0.986+0.004 P v
$$

Landsat-8 TM için YYY; Wang vd. 2015 tarafindan su:0.991, bina:0.962, toprak:0.966, bitki:0.973 değerlerinin kullanılması önerilmiştir. Bu durumda, yukarıda belirtilen NDVI eșik değerleri göz önüne alındığında, toprak için 0.966 yayınırlık değeri, bitki örtüsü için 0.973 yayınırlık değeri kullanılır ve 0,2 ile 0,5 arasındaki NDVI değerleri içinde eșitlik 5 kullanılarak hesaplanmıștır.

\subsection{Kent Alanlarının Haritalandırılması}

Mersin il merkezine ait kent alanlarının çıkartılması için CORINE verilerinden faydalanılmıștır. Doğal alanlar, tarım arazileri, orman vb. alanlar yok edilerek bina, sanayi alanları, çevre yolları gibi ısıl ada etkisi oluşturacak alanlara dönüşmüştür. $\mathrm{Bu}$ yüzden CORINE arazi örtüsü sınıfları içerisindeki 1.1. şehir yapıları, 1.2. endüstri, ticaret ve ulaşım birimleri, 1.3. maden ve inşaat sahaları kapsayan sınıflar kullanılarak 1990 ve 2018 yıllarına ait kentleşme alanları tespit edilmiştir.

\section{BULGULAR}

Landsat-5 TM ve Landsat-8 OLI uydu görüntüleri kullanılarak Mersin ilinin merkezine ait 1990-1999-2007-2011-2018 yıllarını kapsayan çok zamanlı YYS haritaları üretilmiștir. Ayrıca çalıșmada CORINE (1990-2018) verisi kullanılarak kentleşme alanlarının karşılaştırılması yapılmıştır.

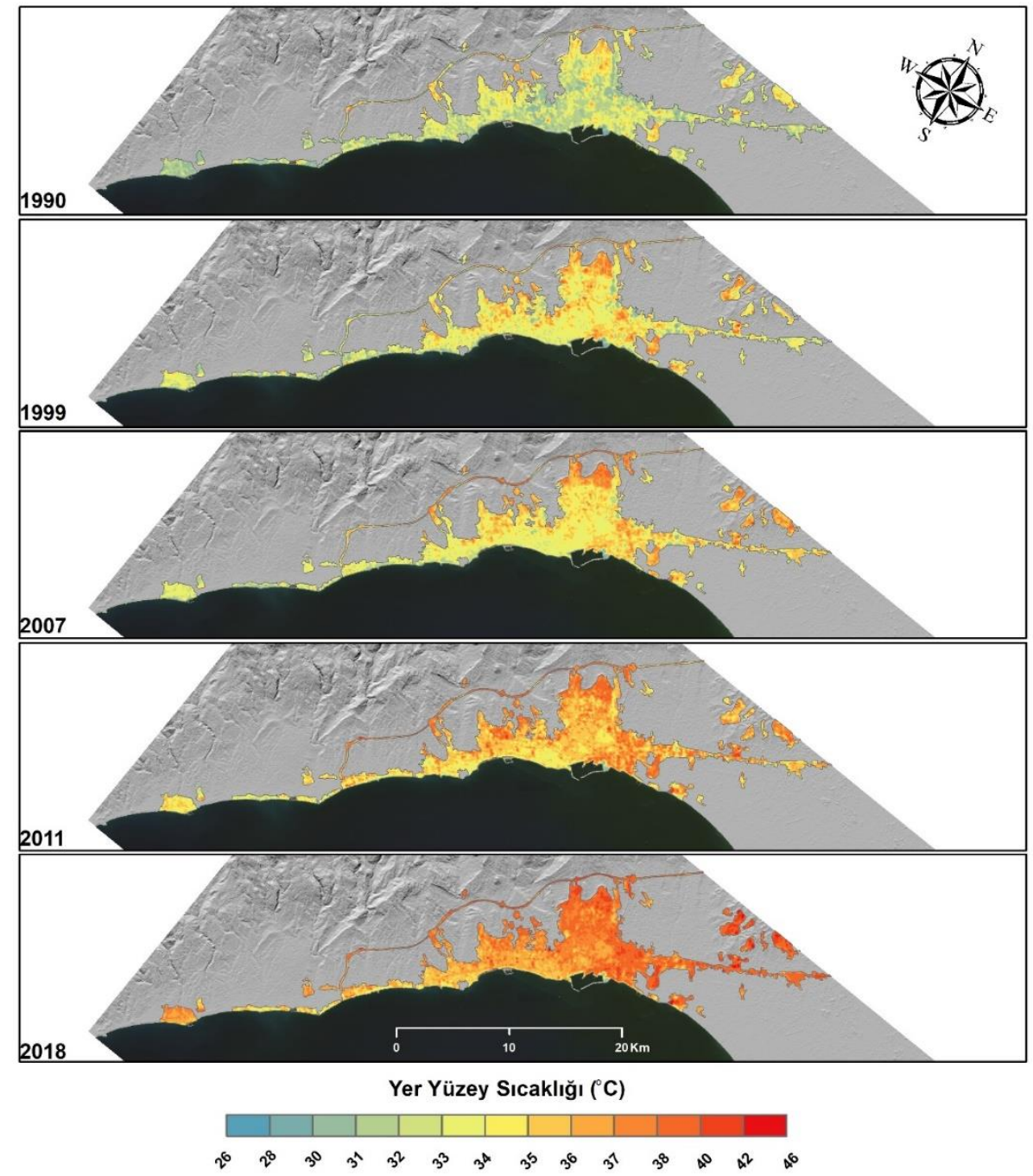

Şekil 2. 1990-1999-2007-2011-2018 yıllarına ait YYS haritaları 
Şekil 2, Landsat-5/8 uydu görüntülerinden elde edilen 1990-1999-2007-2011-2018 ylllarına ait YYS haritalarını göstermektedir. Mersin şehir merkezinin YYS değerlerinde 1990'den 2018 yılına kadar ciddi bir artışın kademeli olarak gerçekleştiği gözlemlenmiştir. 2018 yılında şehir merkezi, diğer yıllara göre en yüksek sıcaklıklara sahiptir. Özellikle şehrin sahil şeridi ve sanayinin bulunduğu doğu kesimlerde 2018'de $42^{\circ} \mathrm{C}$ kadar ulaşan sıcaklık değerleri tespit edilmiştir.

Şekil-2'de şehir merkezinin kuzey kesimleri yeni yapılaşma alanlarını veya kentsel yayılma alanını olușturmaktadır. Ayrıca, Mersin limanın doğu kesimlerini sanayi yerleșkelerini olușturmakta ve bu bölgelerde zamanla hızlı bir gelişme göstermiştir. $\mathrm{Bu}$ yüzden, bu yoğun yapılaşma alanları kentsel ısı adası etkisinden dolayı beklenenden de yüksek sıcaklıklara sahip olmuștur. Erdemli ilçe merkezi (Şekil-2'de sol tarafta yer alan yerleşim alanı) diğer dikkat çeken ısıl ada etkisinin net göründüğü noktalardandır. Bu bölgede $10 \mathrm{C}^{\circ}$ ye ulaşan sıcaklık artışı görülmektedir.
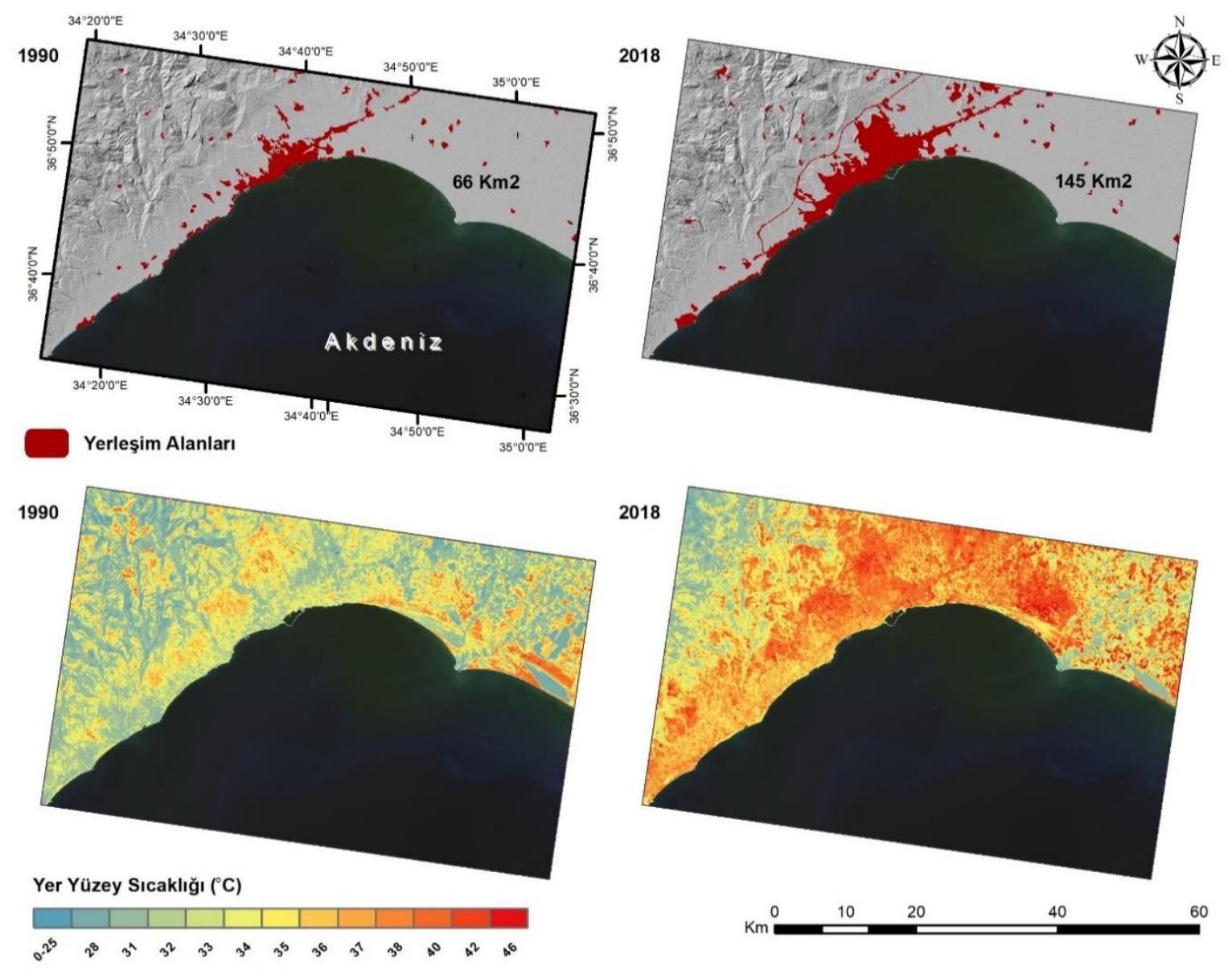

Şekil 3. 1990 ve 2018 yıllarına ait kent alanları (üst) ve YYS haritaları (alt)

Şekil-3 1990 yılı ve 2018 yılı yerleşim alanları ile birlikte o yıllara ait YYS haritalarını göstermektedir. 1990 yılındaki yerleşim alanlarına bakıldığında $66 \mathrm{~km}^{2}$ lik bir alanı kapsarken, 2018 yılında $145 \mathrm{~km}^{2}$ lik bir alana ulașmıștır. Mersin kent merkezi ve çevresindeki yerleşim alanı ve sanayi bölgeleri 28 yıllık bir periyotta iki katından daha fazla yayılmıştır. Diğer bir yandan YYS haritası incelendiğinde kentleşmenin fazla olduğu yer olan sahil şeridinden başlayarak sıcaklığın yoğunlaştığı görülmektedir.

Mersin, Yenișehir ilçesinde bulunan MersinMarina ve yakın çevresin çalışma bölgesi içerisinde en yoğun kentleşmenin görüldüğü alanlardan birini oluşturmaktadır. Şekil-4 incelendiğinde 1990 yılında bölgede görülen yeşil alanların 28 yıllık süre içerisinde neredeyse tamamının bina, yol, iş merkezi, marina, alışveriş merkezi vb. yapay alanlara dönüştügü net şekilde görülmektedir. Bu durum uydu görüntüsü üzerinden net bir şekilde anlaşılırken 2018-1990 YYS fark görüntüsüne bakıldığında da yüzey dokunun ciddi bir şekilde değiştiğimi göstermektedir. Bu bölgede en dikkat çeken noktanın sahil şeridi boyunca yapılan dolgu alanları ve Mersin-Marina'nın oluşturmuş olduğu isı adası net bir şekilde YYS fark görüntüsünde anlaşılmaktadır.

Bitki örtüsünün olduğu yerler beton yapıların olduğu yerlere göre daha serin kalmaktadır. Bunu temel sebebi Kentsel Isı Adası (KIA) etkisidir. Şekil-5 kent merkezinin farklı bölgelerinden elde dilmiş 2018 yılı YYS ve 2018 yılına ait bitki örtüsü 
yoğunluğunu gösteren NDVI profillerini göstermektedir. Şekil-5 (alt)'de yeşil bir koridorun bulunduğu bölgenin $35^{\circ} \mathrm{C}$ gösterirken yerleşim yeri $37.5^{\circ} \mathrm{C}$ göstermektedir. Ayrıca herhangi bir bitki örtüsü bulunmayan açlk alan (parke taşlardan yapılmış park alanı) $40^{\circ} \mathrm{C}$ göstermektedir. Kent merkezlerindeki yeşil koridorların bölgenin KIA etkisini azaltacağ görülmektedir.
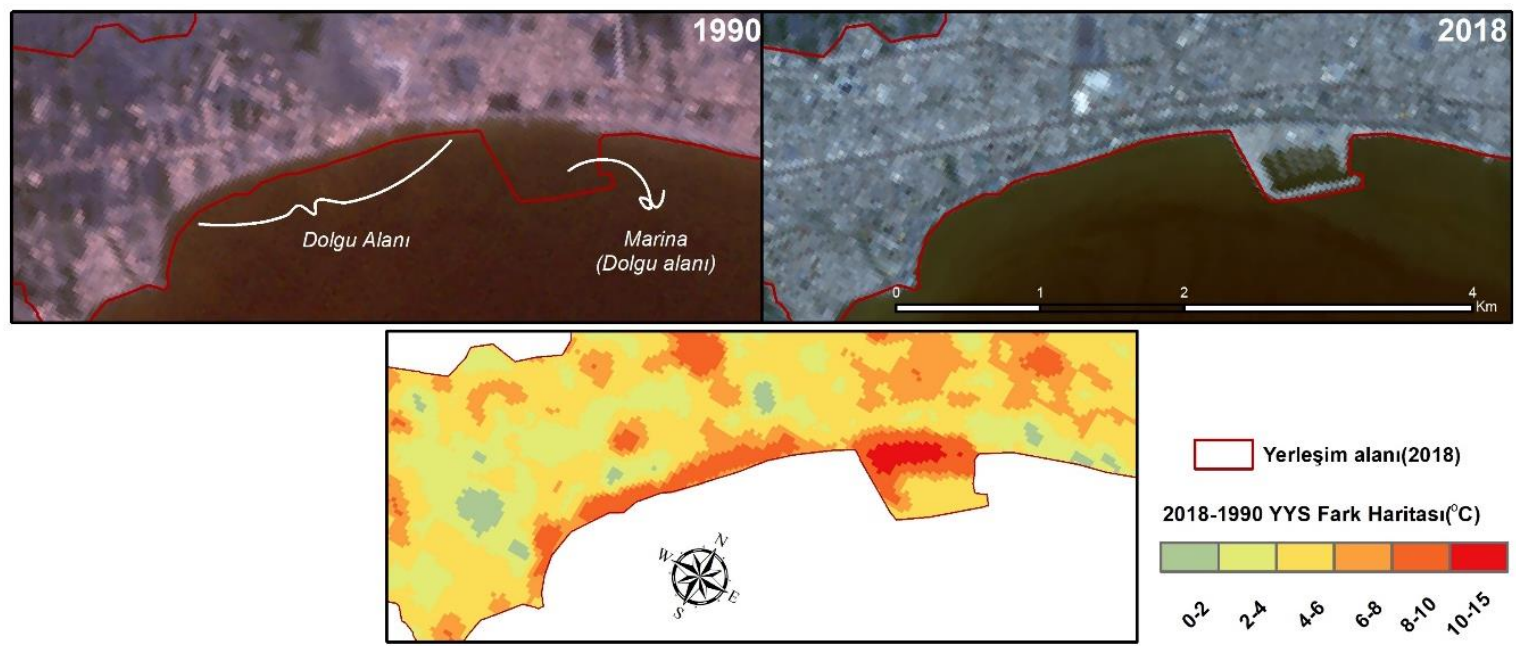

Şekil 4. Mersin- Marina ve çevresindeki kentleşme ve YYS fark görüntüsü

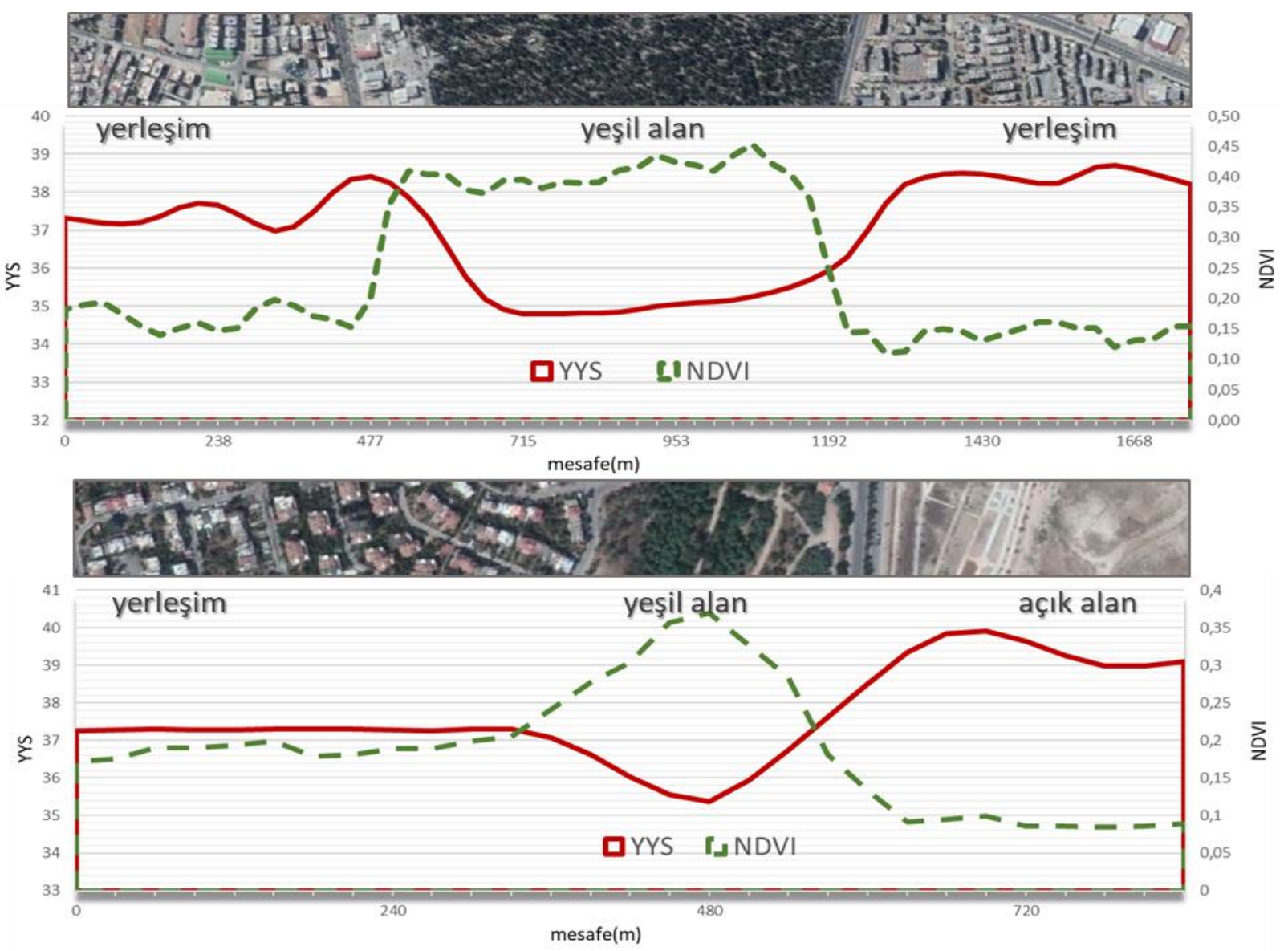

Şekil 5. Kent merkezinin farklı konumlarından alınan 2018 YYS ve 2018 NDVI profilleri

\section{SONUÇLAR ve ÖNERILER}

Güneş enerjisi, orman, tarım arazileri, sulak alanlar, kırsal alanlarda bir engele takılmaz sadece bitki örtüsü ve topraktaki suyun buharlaşmasına neden olurken yoğun kentlerin olduğu yerlerde çok katlı bina, asfalt yollar, sanayi alanları vb. yapılar tarafindan absorbe edilir ve geri yayılması gecikmeye uğrar. Gün boyunca abserbe edilen güneș enerjisi daha sonra ısıya dönüşerek ortama salınır. Kentlerin etraflarındaki kırsal alanlara göre daha sıcak olmasına neden olan bu olaya Kentsel Isı Adası denir. Bu durumda kentlerin kırsal alanlara göre 
daha sıcak olmasına neden olmaktadır (Bayraktar ve Gerçek, 2014). Kent alanlarındaki kentsel ısıl ada etkisinin kurak ve sıcak dönemlerde maksimum olması beklenir (Cui ve de Foy, 2012). Bu nedenle çalışma kapsamında kentleşme sonucu ortaya çıkacak olan sıcaklık değişimini net bir şekilde ortaya koymak için ağustos ayındaki elde edilmiş görüntüler kullanılmaya dikkat edilmiştir.

Kiziroğlu (2017) yılında yayınlamış olduğu “Türkiye'nin Nüfus Değişimine Göre İl Bazında Kentleşmesine Bir Bakış (1965-2014)" başlıklı çalışmasında, 2014 yılı verilerine göre Mersin'in nüfusunun tamamı il ve ilçe merkezlerinde yaşadığı, 1965-2014 yılları arasında nüfusu en fazla artan 10. il olduğu ve 2014 yılından itibaren nüfusa bağlı kentleşme oranının \%100 olduğunu ifade edilmiştir. Yaklaşık olarak 1990 yılında 1 milyon 266 bin nüfusa sahip olan Mersin günümüzde 1.8 milyon bir nüfusa sahiptir. Tabi bu nüfus artışı ile birlikte kent alanlarının artışı kaçınılmaz olmaktadır. 1990 yılından 2018 yılına gelene kadar birçok tarım arazilerinin ve doğal yeşil alanların yok edilerek bina, sanayi, asfalt yol vb. yapay alanlara dönüşmüştür. 1990-2018 yılları arasında yüzey sıcaklık değerleri incelendiğinde ortalama olarak 6 derece civarında sıcaklık artışı olduğu görülmektedir. Sıcaklık değişiminin en şiddetli görüldüğü yer olan Mersin-Marina ve çevresi çalışmada en çok dikkat çeken yer olmaktadır. Bu bölgedeki tüm yeșil alanların beton ve asfalt vb. yüzeylerle yer değiştirmesi ve bu yüzeylerin hızlı bir şekilde sıcaklık değişimine etkisini gözler önüne sermektedir. KIA etkisinin ve lokal iklim değişikliğindeki şiddetin artmasında, genel olarak betonlaşmadaki yoğunluğun artması ve buna bağlı olarak yeşil alan yoğunluğunun azalması önemli bir parametredir (Streiling ve Matzarakis, 2003; Kaplan vd., 2018; Tonyaloğlu, 2019). Mersin kent merkezindeki KIA etkisinin en aza indirgenmesi için yeni planlanacak alanlarda kesinlikle yeşil koridor alanlarının yapı alanları ile makul oranlarda olması, kent merkezlerinde bulunan mevcut yeşil alanlarının çeşitliliğini ve yoğunluğunu artırtmak önemli adımların başında gelmektedir. Daha sonrasında binalarda ve sanayi bölgelerinde kullanılacak olan yüzey malzemelerinde çevreye duyarlı ve KIA etkisini en aza indirgeyecek olanların tercih edilmesi gerekmektedir.

\section{KAYNAKÇA}

Avdan, U., \& Jovanovska, G. (2016). Algorithm for automated mapping of land surface temperature using LANDSAT 8 satellite data. Journal of Sensors, 2016.

Balçik, F. B. (2014). Determining the impact of urban components on land surface temperature of Istanbul by using remote sensing indices. Environmental monitoring and assessment, 186(2), 859-872.
Barsi, J., Schott, J., Hook, S., Raqueno, N., Markham, B., \& Radocinski, R. (2014). Landsat-8 thermal infrared sensor (TIRS) vicarious radiometric calibration. Remote Sensing, 6(11), 1160711626.

Bayraktar, T., N., ve Gerçek, D. (2014). Kentsel Isı Adası Etkisinin Uzaktan Algllama İle Tespiti ve Değerlendirilmesi: İzmit Kenti Örneği. 5. Uzaktan Algilama-CBS Sempozyumu (UZAL-CBS 2014) 14-17 Ekim 2014.

Calò, F., Notti, D., Galve, J. P., Abdikan, S., Görüm, T., Orhan, O., ... \& Şanli, F. B. (2018). A Multi-Source Data Approach For The Investigation Of Land Subsidence In The Konya Basin, Turkey. International Archives of the Photogrammetry, Remote Sensing and Spatial Information Sciences, 42(3/W4).

Chander, G., \& Groeneveld, D. P. (2009). Intra-annual NDVI validation of the Landsat $5 \mathrm{TM}$ radiometric calibration. International Journal of Remote Sensing, 30(6), 1621-1628.

Chander, G., and Markham, B. (2003). Revised Landsat-5 TM radiometric calibration procedures and postcalibration dynamic ranges. IEEE Transactions on Geoscience and Remote Sensing, vol. 41(11), ISSN 0196-2892, p. 2674-2677. doi:10.1109/tgrs.2003.818464

Cui, Y. Y., \& De Foy, B. (2012). Seasonal variations of the urban heat island at the surface and the near- surface and reductions due to urban vegetation in Mexico City. Journal of Applied Meteorology and Climatology, 51(5), 855-868.

Demircan, M., Arabacl, H., Akçakaya, A., Şensoy, S., Bölük, E., \& Coșkun, M. (2017). İklim ve şehirleşme: minimum sicaklık trendleri. IV. Türkiye İklim Değişikliği Kongresi, Bildiriler kitabı, 1-9.

Ekinci, B. (2016). Kentsel Alanlarda Oluşan Isı Adası Etkisinin Kentsel Tasarım Yöntemleri İle Azaltılması: Aksaray Meydanı Örneği. Yüksek Lisans - İstanbul Teknik Üniversitesi, Fen Bilimleri Enstitüsü.

IPCC (2013) Climate Change 2013, The Physical Science Basis, Working Group I Contribution to the Fifth Assessment Report of the Intergovernmental Panel on Climate Change, Cambridge University Press, England.

Kaplan, G., Avdan, U., \& Avdan, Z. Y. (2018, March). Urban Heat Island Analysis Using the Landsat 8 Satellite Data: A Case Study in Skopje, Macedonia. In Multidisciplinary Digital Publishing Institute Proceedings (Vol. 2, No. 7, p. 358). 
Kiziroğlu, A. M. (2017). Türkiye'nin Nüfus Değișimine Göre İl Bazında Kentleșmesine Bir Bakıș (1965-2014). Karadeniz Sosyal Bilimler Dergisi, 9(16), 153-183.

Kuşak, L, Küçükali, U. (2019). Outlier Detection of Land Surface Temperature: Küçükçekmece Region. International Journal of Engineering and Geosciences , 4 (1) , 1-7 . DOI: 10.26833/ijeg.404426

Mersin-ÇDP (2013). Mersin/Adana Planlama Bölgesi 1/100.000 Ölçekli Çevre Düzeni Plani Revizyonu (Mersin Ili) Plan Açiklama Raporu

Moradi, M., \& Görer Tamer, N. (2017). Bursa Örneğinde Kentsel Büyümenin Yerel İklim Değişikliği Üzerine Etkisi. Planlama Dergisi, 27(1), 26-37.

Orhan, O., \& Yakar, M. (2016). Investigating Land Surface Temperature Changes Using Landsat Data in Konya, Turkey. International Archives of Photogrammetry, Remote Sensing and Spatial Information Sciences, 41, B8.

Orhan, O., Dadaser-Celik, F., \& Ekercin, S. Investigating Land Surface Temperature Changes Using Landsat-5 Data And Real-Time Infrared Thermometer Measurements At Konya Closed Basin In Turkey. International Journal of Engineering and Geosciences, 4(1), 16-27.

Orhan, O., Ekercin, S., \& Dadaser-Celik, F. (2014). Use of landsat land surface temperature and vegetation indices for monitoring drought in the Salt Lake Basin Area, Turkey. The Scientific World Journal, 2014.

Özkök, M. K., Tok, E., Gündoğdu, H. M., \& Demir, G. (2017). Arazi yüzey sıcaklı̆̆ farklılaşmalarının kentsel gelişim ve planlama süreçleri açısından uzaktan algılama verileri ile değerlendirilmesi: Çorlu/ Çerkezköy/ Ergene/ Kapaklı alt bölgesi örneği. Toprak Bilimi ve Bitki Besleme Dergisi, 5(2), 69-79.

Pardo-Iguzquiza, E., Atkinson, P.M., Chica-Olmo, M., (2010). Dscokri: a library of Computer programs for downscaling cokriging in support of remote sensing applications. Comput. Geoscience, 36, 881-894.

Sekertekin, A., \& Arslan, N. (2019). Monitoring thermal anomaly and radiative heat flux using thermal infrared satellite imagery-A case study at Tuzla geothermal region. Geothermics, 78, 243-254.
Sekertekin, A., Kutoglu, S. H., \& Kaya, S. (2016). Evaluation of spatio-temporal variability in land surface temperature: a case study of Zonguldak, Turkey. Environmental monitoring and assessment, 188(1), 30.

Sobrino, J.A., Jimenez-Munoz, J. C., Paolini, L. (2004). Land surface temperature retrieval from LANDSAT TM 5. Remote Sensing of Environment, 90, 434-440.

Sobrino, JA, N Raissouni., (2000) 'Toward remote sensing methods for land cover dynamic monitoring: application to Morocco', International Journal of Remote Sensing, 21: 353-66

Sobrino, JA, V Caselles, F Becker., (1990). 'Significance of the remotely sensed thermal infrared measurements obtained over a citrus orchard', ISPRS Journal of Photogrammetry and Remote Sensing, 44: 343-54.

Sobrino, José A, Juan C Jiménez-Muñoz, Guillem Sòria, Mireia Romaguera, Luis Guanter, José Moreno, Antonio Plaza, Pablo Martínez., (2008) 'Land surface emissivity retrieval from different VNIR and TIR sensors', IEEE Transactions on Geoscience and Remote Sensing, 46: 316-27

Streiling, S., \& Matzarakis, A. (2003). Influence of single and small clusters of trees on the bioclimate of a city: a case study. Journal of Arboriculture, 29(6), 309-316.

Şekertekin, A., \& Marangoz, A. M. (2019). Zonguldak Metropolitan Alanındaki Arazi Kullanımı Arazi Örtüsünün Yer Yüzey Sicaklığına Etkisi. Geomatik, 4(2), 101-111.

Tonyaloğlu, E. E. (2019). Kentleşmenin Kentsel Termal Cevre Üzerindeki Etkisinin Değerlendirilmesi, Efeler ve İncirliova (Aydın) Örneği. Türkiye Peyzaj Araştırmaları Dergisi, 2(1), 1-13.

Wang, F., Qin, Z., Song, C., Tu, L., Karnieli, A., \& Zhao, S. (2015). An improved mono-window algorithm for land surface temperature retrieval from Landsat 8 thermal infrared sensor data. Remote Sensing, 7(4), 4268-4289.

Yüksel, Ü. D., \& Yilmaz, O. (2008). Ankara kentinde kentsel ısı adası etkisinin yaz aylarında uzaktan algılama ve meteorolojik gözlemlere dayalı olarak saptanması ve değerlendirilmesi. Gazi Üniversitesi Mühendislik-Mimarlık Fakültesi Dergisi, 23(4). 